AperTO - Archivio Istituzionale Open Access dell'Università di Torino

Book Review: When mathematics and mathematics education come to matter: A review of Elizabeth de Freitas and Nathalie Sinclair's Mathematics and the Body: Material Entanglements in the Classroom (2014)

This is the author's manuscript

Original Citation:

Availability:

This version is available http://hdl.handle.net/2318/1564834

since 2017-03-29T17:37:42Z

Published version:

DOI:10.1007/s10649-015-9619-x

Terms of use:

Open Access

Anyone can freely access the full text of works made available as "Open Access". Works made available under a Creative Commons license can be used according to the terms and conditions of said license. Use of all other works requires consent of the right holder (author or publisher) if not exempted from copyright protection by the applicable law. 


\section{(5) \\ UNIVERSITÀ DEGLI STUDI DI TORINO}

The final publication is available at Springer via http://dx.doi.org/10.1007/s10649-015-9619-x

Ferrara, F. (2015). Book Review: When mathematics and mathematics education come to matter: A review of Elizabeth de Freitas and Nathalie Sinclair's Mathematics and the Body: Material Entanglements in the Classroom (2014). Educational Studies in Mathematics, 90(2), 215-220 


\title{
Book Review: When mathematics and mathematics education come to matter: A review of Elizabeth de Freitas and Nathalie Sinclair's Mathematics and the Body: Material Entanglements in the Classroom (2014)
}

\author{
Cambridge: Cambridge University Press. Learning in Doing: \\ Social, Cognitive and Computational Perspectives. 284 pages. \\ Hardcover: ISBN: 978-1-107-03948-3 List price 99 US\$
}

\author{
Francesca Ferrara ${ }^{1}$
}

In the last two decades or so, embodied cognition theorists have drawn attention to the role of the body and embodiment in mathematics thinking and learning, troubling some of the longstanding idealist assumptions that characterise the twentieth century mathematics as a disembodied abstract edifice of foundational rigour, which ignores corporeality in toto. Lakoff and Núñez's (2000) contention that mathematical abstractions are grounded in the sensory-motor system and in our interaction with the material world through metaphors was intriguing, in a time when psychological research was bringing forth insights about the indissoluble unit between thought and gesture. We acquired much more of a sense that we could not talk about mathematics without talking about the body in mathematics. But this metaphorical thought approach entailed mental schemas or structures behind the mathematics, presupposing the delicate issue of representation, and failing to really go beyond the binary divide of body/mind that it was trying to question. The 'turn to bodily activity' did not take long to follow. Through empirical studies, more directly speaking to the body's engagement with mathematical concepts and to mathematical activity, mathematics educators started looking at gestures and tactile-kinesthetic, perceptuo-motor experiences as multimodal means of understanding, and constitutive of thinking and of a mathematical cognition that Radford (2014) has ultimately termed "sensuous". In recent times, the question of embodiment has grown in nature and complexity, being no longer one of charting correspondences between visible physical activity and inferred, formal mathematical thought (finally exhausted by mechanisms in the mind). Rather, one of the biggest challenges to contemporary embodied accounts of cognition seems to be avoiding lapsing into dualist views of perceptual/sensual

Francesca Ferrara

francesca.ferrara@unito.it 
and conceptual, outer and inner, as well as of the material world - of which our body and concrete materials are part - and thought and the mathematics. The issue itself of subjectivity, that of the very identity of the self, which regards the body, has become problematic since the advent of the lattice of information and communication technologies and within the contemporary digitally enabled scene. As Rotman (2008) has pointed out, it is not even nor really a question of identity, "of 'who' the emergent self is, but what and how is this self" and of how it is "assembled and transformed" (p. 81, emphasis in original) by the technological ecologies in which we are immersed, always "in the process of becoming beside itself" (p. 103).

Elizabeth de Freitas and Nathalie Sinclair face the challenge in Mathematics and the Body: Material Entanglements in the Classroom, focusing on the entanglement of concepts, language and the material world, through a turn to posthumanist discourses of subjectivity and agency. The book takes on a philosophical perspective, a particular brand of materialism called inclusive materialism, to de-essentialise the notion of the body in its traditional form and to examine in what sense and how mathematics partakes of the material world; also, rethinking the way human beings interact with matter. The authors elaborate further "on Rotman's sense of the body as that which is always becoming", proposing a new, extended conception for which "the body need not be delimited by the container of its skin, nor should the concept of the body be exclusively reserved for sentient beings" (p. 5). The idea of posthumanism that is accordingly developed appears as a counter-intuitive one to grasp, moving away from the "common-sense inclination to centre the human subject in the study of teaching and learning" (p. 4), and instead distributing agency and thought across multiple sources in the mathematical situation.

Chapter 1, When does a body become a body?, shows that boundaries are re-created and assemblages emerge as the body, and as the unit of analysis, in the learning experience of students working with tools or concepts. In doing so, it opens room for challenging the methodological issues, faced throughout the book, about what constitutes research data and how to look at the data. Interestingly, the authors state that assemblages "are also saturated and sustained by the non-visible, be it sonic, haptic, olfactory or some other material percept. They are not simply cobbled together with discrete add-ons of parts, be they goblets, organs or concepts, but are always in motion, growing and contracting" (p. 34). Thus, attention is directed more to the becoming of the body than its being, a process that emphasises the potentiality of the body. One of the strengths of this posthumanist idea is in its powerful orientation towards addressing the collective social body, which is often under-considered from many current theories of embodiment that, by analysing student activities, are mainly limited to accounting for individual processes of learning. Another strength is in its subtle consideration of the interactionist view that materials are not inert but are constantly interacting with each other and with the human body. This is a view that theorises the role of materials in learning mathematics differently from the conceptualist idea of the traditional cognitivist approach for which materials have confined properties of their own.

What is meant by activity, learning and embodiment is troubled in terms of the open whole of inextricable relations between all the human and non-human components that are present in the situation. Within an empiricist tradition, de Freitas and Sinclair (re)interpret with their lines of flight various episodes from the mathematics classroom, some of which come from other publications or resources in the field. These episodes are useful to allow readers to enter into various thought experiments about alternative ways of thinking of the relationship between mathematics and matter, the mathematical and the physical, the abstract and the concrete, and 
the learner and learning. So, the writing surface or the limited desk with which students work in the goblet-chip example - where students use bingo chips and number plastic goblets to model a figural patterning process from week 1 to 5-are implicated, as part of the material practice, in the assembling of meaning and can entail the creation and exploration by learners of new unexpected temporal and spatial dimensions, which contract and expand the bodyassemblage in an ever-flowing process. The examples also embed some of the implications of inclusive materialism in relation to teaching and learning mathematics. For instance, had the writing surface instead been a flat and wide interactive whiteboard or a tablet screen, or "had the students placed the chips differently [...], the assembling of matter and meaning would have changed" (p. 30). The particular material conditions would have entailed different teacher/student gestures and intonations. Apart from shedding light on a new way of studying how students learn concepts, this perspective might also entail insights on the design of tasks, an issue that is still under-debated in the literature but is becoming more and more relevant both methodologically (for practice) and analytically (for research). However, the book remains almost silent about task design, although reflections on the related pedagogy of the concept are present, as in the case of rethinking extension or the concept of zero, in terms of their intrinsic ontological indeterminism, and more as intensities than entities (here, I use the idea of intensity as that which reverberates with movement, while entity echoes fixity). In these terms, the issue of task design is also linked to discourse on the curriculum mapping of mathematical concepts (the choice and order of curricular concepts of Chapter 8), so it could be a fruitful area for future research in an inclusive materialist view. If it is true that "when concepts are animated differently, learning is similarly altered" (p. 12), we might want to ask: Which kind of tasks would effect learning as a matter of mobile animated concepts?

The book is an invitation to learn "more about how mathematics and the human body consort" (p. 4) and wants to say something about "how mathematical concepts such as number can inhabit the physical world rather than some metaphysical, Platonic realm" (p. 6). In doing so, another seemingly counter-intuitive idea regards the extension of "materiality [as] beyond the strict confines of concrete, physical objects so that meaning, discourse and concepts are also treated as material” (p. 3). This entails the ontological entanglement of matter and meaning outlined in Chapter 2, especially through the work of Barad on quantum physics. Despite its unusual nature, the strengths of this idea are in its ontological claim about the nature of mathematical concepts not as universal, abstract and static, but as vibrant, vital and partaking of the physical world, thus overcoming the idealistic Aristotelian vision of a detemporalised and immovable mathematics distinct from movable matter. Instead, the inclusive materialist view allows revitalisation of the concept with respect to its vitality, potentiality, mobility, temporality, force, energy, intensity, affect and inventiveness. This is from where de Freitas and Sinclair come to speak of the body of mathematics, not only of the body in mathematics thinking, as the discussion exploits in Chapter 8. A body that, drawing on Deleuze and Guattari (1987), is always multiplicity: bodies, "ceaselessly in motion, moving, shifting and changing, playing out as a force-field of 'microprocesses', and 'a myriad of intensities and flows"' (Grosz, 1994, p. 181); a body that is also always virtuality: a potential "pressing crowd of incipiencies and tendencies" (Massumi, 2002, p. 3); and a mathematics that is also multiple and virtual, in its being mobile. A mathematics that, after reading the book and knowing about Châtelet's (1993/2000) interests in the gesture/diagram interplay and in the actualisation of the virtual (Chapters 3 and 4), I see as event and invention, rather than silently standing there and existing: a mathematics that occurs and transforms, which comes to matter. Attention is clearly shifted away from the doer of mathematics - be she the student or the 
mathematician - to focus on the doing of mathematics. De Freitas and Sinclair consider the activity of doing mathematics as a cultural material practice, in which sensory activity determines "how mathematical engagement operates on various material planes" (p. 230). Diagramming and discursive practices are two examples. The authors present the materiality of diagrams as a consequence of the relational ontology with gestures and the subsequent sociomaterial rethinking of inventiveness in the mathematics classroom, for which learning is the creation of the new (see Chapter 4, Inventiveness in the mathematics classroom). The materiality of language is instead discussed through the analysis of "ways of talking" in mathematics (the human voice and its prosodic effects) by means of the lecture example presented in Chapter 5, Materialist approaches to mathematics classroom discourse. Through this analysis, the authors shed light on speech's own creative material force with its particular set of potentialities and "micro-gestures of intonation and stress. The binding of sound and meaning in the classroom has to be examined at this micro-level and analysed for how affect and rhythm, together with other sonorous facets of sound, produce meaning" (p. 131). Paying attention to aspects such as pauses, accelerations and temporal modulations of speech in the learning assemblage, the inclusive materialist framework recognises the affective forces that circulate in the classroom alongside the spoken word. This "micropolitics of classroom discourse" again decentres the subject as the source of meaning and offers a way of studying language as in(ter)vention rather than communication. Such vision problematises our usual practices in educational research, especially in relation to data transcription but also to our own discursive practices (ways of talking).

This discourse is intriguing in light of recent enactivist-inspired approaches to analysing data, in which the vision that doing is knowing and vice versa is strongly affirmed. These approaches attempt to imagine possibilities for mathematics education rather than arguing for or against taken-for-granted practices. Thus, the researcher's observations/descriptions do not concern issues of knowledge and acquisition (so that engaging with a task is not a representation of one's capacity for knowing or internal processes), but mathematical activity itself, the emergent learners' actions, the local mathematical doings as the doing of mathematics. Maheux and Proulx (2015) use the concept of "doing|mathematics, an expression that alludes to the emergent made-up nature of both the doing and the mathematics and their dialectical relationship in lived-life mathematical experience" (p. 214). With this focus, research work leads "to develop[ing] ways of talking about mathematical doings while avoiding ideas of possession (acquisition of, choice of, 'having' things, etc.), and rather talking in terms of flux, movement, relations, actions, and so forth" (p. 214). This view analyses how interactions contribute to bringing forth doing|mathematics, and, conversely, how doing|mathematics pushes researchers to look at interactions in the mathematics classroom. De Freitas and Sinclair wish to study the relational impersonal forces that circulate in interaction and the material ontology of doing|mathematics, for which both mathematics and the doer of mathematics are in motion, in a process of change and alteration: "The mathematical body comes into being through actualizing the virtual - through gestures, diagrams and digital networks, we become mathematics; we incorporate and are incorporated by mathematics. The assemblage grows" (p. 213).

The concern with practices also reminds me of a chapter I read very recently, which tries to reconsider the question of how practice and the body in professional education might come together, conceptually and empirically (Green, 2015). Consistent with a Deleuzian account of the body, Green conceives of practice "as characterised by becoming-ness, and even, indeed, at times becoming-other" (p. 123), decentring practice from the human and moving the study of 
practices "into a fuller engagement with the socio-materiality of the extra-human world" and "to notions of mutability, emergence, complexity, flow and becoming" (p. 124). I was surprised to find this discourse aligned with what is called in the study "practice ontology" and with the idea of "practice-ing", which suddenly brought me back to the ontological demands of inclusive materialism in relation, for example, to discourse and diagramming and also to our research practices. I have been intrigued by its taking on a non-representational perspective on practice oriented to a richer and more dynamic understanding of corporeality than in the traditional sense. Grosz (1994) comes back again in focusing on "the capacities and unknown potential of the body, to do things, to engage in practices" (pp. 168-169), and practice itself is soon reconceptualised in terms of "the "energetics" of the body", as "the body in motion, or movement, becoming-body" (Green, 2015, p. 127). While the example offered by Green in his work focuses on the practising teacher, as an embodied professional, the teaching body with regard, in this case, to the teaching of reading, accent is also put on the "other and indeed multiple bodies", which are understood "as learning bodies, precisely because they are in practice, moving, feeling, etc." (p. 133, emphasis in the original). De Freitas and Sinclair would agree with Green in his rethinking of the body, which "makes it possible to think outside and beyond not simply what might be called the anthropomorphic body, but also the realist, representational body - the body of commonsense and of orthodoxy" (p. 133). If the study encourages a more flexible, creative and transformative vision of practice and the body in professional education, and a conception of learning as a matter fundamentally of actualisation, an inclusive materialist view might be interested in asking: Which kind of actualisations would the teacher pursue in the mathematics classroom?

This book makes a crucial contribution to the field because of the way it radically disrupts the discourses of abstraction, generalisation or representation in relation to mathematics and mathematics education, in favour of discourses of materiality, movement, flow and affect in the mathematics classroom. Readers from all over the world can learn considerable lessons from this study of mathematics and the body. Beyond being a posthumanist approach to the body and matter, the inclusive materialism is a posthumanist vision of perception and sensation. One of the more controversial but also, I believe, promising ideas is, in Chapter 6, the one of freeing "the body from the confines of current regimes of perception" (p. 140), and recognising "the human body in all its potentiality, even in our current classrooms, where bodies can be seen as differently abled and differently (organ)ised rather than disabled or distracted" (p. 140). This is a way of rethinking sense and perception that decentres the sensory organs calling for the provisional and indeterminate nature of sensation. The glimpsed tentative move to rethinking (dis)ability is a challenge for the understanding of the human body, being concerned with a question of value: what counts as (dis)abled in our classrooms and in life, what 'matters' once again. De Freitas and Sinclair question the very borders between the abled and the (dis)abled, avoiding to assign disability to the individual. Their discussion is an enchanting and brave attempt to touch the delicate terrain that current debates on disabilities are bringing forth, especially with respect to matters of accessibility and inclusiveness in education. The subtle exploration of what is taken to be sensible and makes sense, both in mathematics and in mathematics education, couples aesthetic and political aspects of cultural practices, like those of school mathematics or mathematics education (usually practices of consensus). The provocative thought that we should speak of communities of sense rather than of practice and 'practice' acts of dissensus comes with a reconfiguration of the mathematical aesthetic (Chapter 7). In the conclusions, the authors very quickly put forward another issue of fascinating interest, which they do not face in the book despite its 
relevance in a posthumanist perspective: gender. They conclude by saying that they recognise the need to address it and encourage other researchers to join them "in exploring the complex ways in which bodies are configured according to prevalent tendencies, like gender" (p. 231).

The book is ambitious and provocative in its purpose of developing an inclusive materialist philosophy of mathematics. I really enjoyed the insightful writing, so carefully devoted to furnish theoretical tools to the readers. I also enjoyed reading and giving into the challenging arguments and episode discussions. I was affected throughout the process, and transformed as I read and re-read, coming to a better understanding of both the perspective and myself. I gain more awareness of my own being in motion, in a process of becoming, as researcher interested in what it might matter in mathematics teaching and learning, in mathematics thinking. For this same reason, I recommend the book to teachers, teacher educators, researchers and mathematicians, who want to contemplate alternative lines of flight towards enlivening both mathematics and mathematics education, and telling new stories about mathematical events. Because-we know - "It is the story that matters, not just the ending" (Paul Lockhart, as cited at p. 215, emphasis in the original).

\section{References}

Châtelet, G. (1993/2000). Figuring space: Philosophy, mathematics, and physics. (R. Shore \& M. Zagha, Trans.). Dordrecht, The Netherlands: Kluwer. (Original work published as Les enjeux du mobile, 1993).

Deleuze, G., \& Guattari, F. (1987). A thousand plateaus: Capitalism and schizophrenia. Minneapolis, MN: University of Minnesota Press.

Green, B. (2015). Thinking bodies: Practice theory, Deleuze and professional education. In B. Green \& N. Hopwood (Eds.), The body in professional practice, learning and education. Dordrecht, The Netherlands: Springer.

Grosz, E. (1994). Volatile bodies: Toward a corporeal feminism. Bloomington, MN: Indiana University Press.

Lakoff, G., \& Núñez, R. (2000). Where mathematics comes from: How the embodied mind brings mathematics into being. New York, NY: Basic Books.

Maheux, J.-F., \& Proulx, J. (2015). Doing|mathematics: Analysing data with/in an enactivist-inspired approach. ZDM-The International Journal on Mathematics Education, 47(2), 211-221.

Massumi, B. (2002). Parables for the virtual: Movement, affect, sensation. Durham, NC: Duke University Press.

Radford, L. (2014). Towards an embodied, cultural, and material conception of mathematics cognition. ZDMThe International Journal on Mathematics Education, 46(3), 349-361.

Rotman, B. (2008). Becoming beside ourselves: The alphabet, ghosts, and distributed human beings. Durham, NC: Duke University Press. 